\title{
An Empirical Study on the Key Factors of College Students' Entrepreneurial Success
}

\author{
Yuhang Zhou ${ }^{1, a^{*}}$ and Yu Bai ${ }^{1, b}$ \\ ${ }^{1}$ School of Management, Wuhan University of Technology, Wuhan, China \\ a893179906@qq.com, bbaiyu_whut@163.com
}

\begin{abstract}
Keywords: University students' innovative undertaking; Elements of success; Empirical research; Countermeasure research; Wuhan city
\end{abstract}

\begin{abstract}
College students' entrepreneurship has been widespread concern and support from all sectors of society. But on the whole, the success rate of College Students' entrepreneurship is low. It is a waste of valuable resources such as time and money. Aiming at the problem, this questionnaire takes 200 college students entrepreneurial enterprises in Wuhan City as a sample. Discuss from dimensions such as companies, government, colleges and universities. Analyze the factors that influence the success of College Students' Entrepreneurship innovatively. Get the driving factors and obstacles to its success. The study found that set up the college students' entrepreneurship support platform by government, constructing the system of Cultivating College Students' entrepreneurial ability, make full use of industry-university interaction in the promotion role and strengthen the construction of enterprise internal environment are effective countermeasures. Provide a reference for college students successful entrepreneurship.
\end{abstract}

\section{Introduction}

In the internationally recognized entrepreneurial era. The world's economic powers are respected independent entrepreneurship. Young people's whimsy will inject vitality into the whole economy. The 18th National Congress of the Communist Party of China put forward that employment is the people's livelihood, to be committed to high-quality employment. It can be seen that the party and the government attach great importance to the employment of college students. Although scholars both at home and abroad have been studying entrepreneurship, the influence factors in the success of the venture entrepreneurs, especially college students' entrepreneurs. There are few useful references and references for college students.

Under the is not optimistic employment situation, more and more college students want to achieve self value through entrepreneurship. But often retreat because of the low success rate of entrepreneurship. The study of college students the factors that affect the success of entrepreneurship is clearly imminent[1].

The factors of College Students' entrepreneurial success, could guide college students to start their own business effectively in a sense, avoid detours. Students can have intention to start early attention to improve their quality, to succeed in business practice foundation. This can also fundamentally solve the real problems faced by entrepreneurs. Students can find more suitable for their jobs, industry and the salary. To achieve the aim of effective configuration of human capital[2].

The social from all walks of life has given more and more support for college students' entrepreneurship. College students as the main force of entrepreneurship, who have received a good entrepreneurship education in colleges, have their innate advantages and disadvantages. We should try to analyze these advantages and disadvantages to help them understand the current entrepreneurial environment, improve their own entrepreneurial qualities. Focus on and study the important factors of entrepreneurial success to improve the success rate of college students' entrepreneurship. Therefore, it is necessary to study the key factors of entrepreneurial success and the research space in this area is still very large. 


\section{Literature Review}

The Definition of Entrepreneurial Success. For the success of entrepreneurship, the academic community is generally considered to be related to personal resources, and personal resources can be inherent in the entrepreneur itself, but also can be obtained from the subjective initiative. And then through the use of resources to make the economic value and social value[3]. Some scholars believe that entrepreneurial success is the sustainable development of the company, and the financial balance of payments surplus or surplus of a large number of entrepreneurs and start-ups. The entrepreneurial success in this study is that start-ups can operate self-sufficiency, or have established a mature profit model, is expected to grow in the real fast, and can achieve healthy development[4].

The Influence Factors of College Students' Entrepreneurial Success. Through the statistical analysis of relevant research can be found that the research on the influence factors of college students' entrepreneurial success is less. Many studies have focused on the entrepreneur, government and social environment.

There are 4 main factors that influence the success of entrepreneurship in the enterprise dimensions, including enterprise internal system, enterprise maturity, enterprise staff quality and enterprise stability[5]. The internal system of the enterprise includes the factors such as the degree of function setting, the performance evaluation, the diversity of incentive measures, and the clear corporate culture. While enterprise maturity is measured by internal collaboration and strategic planning; The quality of the staff is divided into the proportion of experienced members, the degree of professional relevance and innovation ability, the stability of the enterprise is divided into the stability of the working environment and the level of employee turnover[6].

The problem of capital is the bottleneck that college students often encounter in the start-up stage, Many entrepreneurs in the beginning have encountered problems such as lack of funds and liquidity. As the booster of college students, the government should give support to college students in all aspects, Especially in terms of funding, the government should provide financial support to college students in the initial stage of entrepreneurship[7]. The study found that the main factors affecting the success of entrepreneurship, including financial subsidies, publicity, management services, tax incentives and the construction of business parks.

Pre industry education, work practice, entrepreneurship competition and entrepreneurship seminars have a positive impact on the success of College students' entrepreneurial success[8].

\section{Data and Results Analysis}

The study was conducted through questionnaires and case interviews with the use measurement tools for statistical survey data, made a systematic analysis of the factors that influence the success of college students from the 3 dimensions of enterprises, government and universities.

The Sample. In this paper, we choose the entrepreneurial or entrepreneurial team of the university students in Wuhan as the sample and made depth interviews with 30 entrepreneurs or entrepreneurial team members. 200 questionnaires were distributed, and 113 questionnaires were collected, and the recovery rate was up to $56.5 \%$, of which there were valid questionnaires of 94 , the effective rate was up to $83.19 \%$.

Questionnaire Design. Through the previous literature review and in-depth interviews with entrepreneurs, We establish the factors that affect the success of college students under the three categories of factors and factors of refinement indicators, as shown in Table 1. 
Table 1 Influence factor and refinement index

\begin{tabular}{|c|c|c|}
\hline influence factor & & refinement index \\
\hline \multirow{11}{*}{$\begin{array}{l}\text { Enterprise } \\
\text { dimensions }\end{array}$} & \multirow{4}{*}{$\begin{array}{l}\text { Enterprise internal } \\
\text { system } U_{1}\end{array}$} & The completeness of the function settings $U_{11}$ \\
\hline & & performance appraisal $\mathrm{U}_{12}$ \\
\hline & & Clear corporate culture $\mathrm{U}_{13}$ \\
\hline & & The degree of diversity of incentive measures $U_{14}$ \\
\hline & \multirow{2}{*}{ Enterprise maturity $\mathrm{U}_{2}$} & Internal collaboration $\mathrm{U}_{21}$ \\
\hline & & strategic planning $\mathrm{U}_{22}$ \\
\hline & \multirow{3}{*}{$\begin{array}{l}\text { Enterprise staff quality } \\
\qquad \mathrm{U}_{3}\end{array}$} & The proportion of experience members $U_{31}$ \\
\hline & & Degree of professional correlation $U_{32}$ \\
\hline & & Innovation ability $\mathrm{U}_{33}$ \\
\hline & \multirow{2}{*}{ Enterprise stability $\mathrm{U}_{4}$} & Stability of working environment $\mathrm{U}_{41}$ \\
\hline & & Level of staff turnover $\mathrm{U}_{42}$ \\
\hline \multirow{5}{*}{$\begin{array}{l}\text { Government } \\
\text { dimensions }\end{array}$} & & Fund subsidy $\mathrm{U}_{5}$ \\
\hline & & Propaganda dynamics $\mathrm{U}_{6}$ \\
\hline & & management service $\mathrm{U}_{7}$ \\
\hline & & Tax incentives $\mathrm{U}_{8}$ \\
\hline & \multicolumn{2}{|c|}{ Construction of Pioneering Park $\mathrm{U}_{9}$} \\
\hline \multirow{4}{*}{$\begin{array}{l}\text { University } \\
\text { dimensions }\end{array}$} & \multicolumn{2}{|c|}{ Pre service education $\mathrm{U}_{10}$} \\
\hline & \multicolumn{2}{|c|}{ Work practice $\mathrm{U}_{11}$} \\
\hline & \multicolumn{2}{|c|}{ Entrepreneurship Competition $\mathrm{U}_{12}$} \\
\hline & \multicolumn{2}{|c|}{ Entrepreneurship lectures $\mathrm{U}_{13}$} \\
\hline
\end{tabular}

Take the enterprise dimension as an example, from table 1 we can see that questionnaire design project contains 4 categories for 11 events. The questionnaire was set up according to the Likert 5point scale, Score from 1 to 5, Represents a total of 5 levels of change from "very low" to "high". Invite respondents to fill in questionnaires according to their own needs and perceptions.

The Data Processing. Based on the data from in-depth interviews, four categories of indicators can be obtained U1, U2, U3, U4 and its weight, as shown in Table 2

Table 2 The weight vector of enterprise dimensions

\begin{tabular}{|c|c|}
\hline Criterion layer & Weight vector \\
\hline $\mathrm{U}\left(\mathrm{U}_{1} 、 \mathrm{U}_{2} 、 \mathrm{U}_{3} 、 \mathrm{U}_{4}\right)$ & $(0.297,0.248,0.112,0.163)$ \\
\hline
\end{tabular}

Based on the results of questionnaire survey and statistical analysis, the score matrix of influencing factors can be obtained, as shown in Table 3.

Table 3 Weight statistics of the survey results

\begin{tabular}{|c|c|c|c|c|c|c|}
\hline \multirow{2}{*}{$\begin{array}{c}\text { Enterprise } \\
\text { dimensions }\end{array}$} & $\begin{array}{c}\text { refinement } \\
\text { index }\end{array}$ & \multicolumn{5}{|c|}{ Score } \\
\cline { 2 - 6 } & $\mathrm{U}_{11}$ & 5 points & 4 points & 3 points & 2 points & 1 point \\
\cline { 2 - 6 } & $\mathrm{U}_{12}$ & 0.096 & 0.324 & 0.237 & 0.166 & 0.112 \\
\cline { 2 - 6 } & $\mathrm{U}_{13}$ & 0.078 & 0.117 & 0.328 & 0.289 & 0.170 \\
\cline { 2 - 6 } $\mathrm{U}_{1}$ & $\mathrm{U}_{14}$ & 0.136 & 0.256 & 0.287 & 0.203 & 0.118 \\
\hline \multirow{3}{*}{$\mathrm{U}_{2}$} & $\mathrm{U}_{21}$ & 0.289 & 0.394 & 0.132 & 0.102 & 0.083 \\
\cline { 2 - 7 } & $\mathrm{U}_{22}$ & 0.205 & 0.341 & 0.257 & 0.116 & 0.081 \\
\hline \multirow{3}{*}{$\mathrm{U}_{3}$} & $\mathrm{U}_{31}$ & 0.082 & 0.156 & 0.348 & 0.291 & 0.123 \\
\cline { 2 - 6 } & $\mathrm{U}_{32}$ & 0.093 & 0.173 & 0.336 & 0.218 & 0.180 \\
\cline { 2 - 6 } & $\mathrm{U}_{33}$ & 0.063 & 0.127 & 0.238 & 0.389 & 0.183 \\
\hline \multirow{2}{*}{$\mathrm{U}_{4}$} & $\mathrm{U}_{41}$ & 0.112 & 0.193 & 0.287 & 0.325 & 0.083 \\
\cline { 2 - 6 } & $\mathrm{U}_{42}$ & 0.196 & 0.258 & 0.303 & 0.176 & 0.067 \\
\hline
\end{tabular}


Refine each index weight in the form of matrix, As the A matrix . The evaluation grade of questionnaire can be set up $\mathrm{B}$ matrix, $\mathrm{B}=[5 ; 4 ; 3 ; 2 ; 1]$. And use MATLAB software for matrix processing, can $A, B$ matrix can be multiplied by the results that matrix $\left[\mathrm{U}_{11} ; \mathrm{U}_{12} ; \mathrm{U}_{13} ; \mathrm{U}_{14}\right]$, matrix $\left[\mathrm{U}_{21} ; \mathrm{U}_{22}\right]$, matrix $\left[\mathrm{U}_{31} ; \mathrm{U}_{32} ; \mathrm{U}_{33}\right]$, matrix $\left[\mathrm{U}_{41} ; \mathrm{U}_{42}\right]$, The following matrix results can be obtained by MATLAB treatment, as shown in Table 4.

Table 4 The processing results of each subdivision index

\begin{tabular}{|c|c|}
\hline $\mathrm{C}_{1}$ & {$[3.2560 ; 2.6800 ; 2.7470 ; 3.0890]$} \\
\hline $\mathrm{C}_{2}$ & {$[3.7040 ; 3.4730]$} \\
\hline $\mathrm{C}_{3}$ & {$[2.7830 ; 2.7810 ; 2.4980]$} \\
\hline $\mathrm{C}_{4}$ & {$[2.9260 ; 3.3400]$} \\
\hline
\end{tabular}

The matrix is further processed, then get the weight assignment matrix of each index, as shown in Table 5.

Table 5 The weight assignment matrix of each refinement index

\begin{tabular}{|c|c|}
\hline $\mathrm{C}_{1}$ & {$[0.2766 ; 0.2277 ; 0.2333 ; 0.2624]$} \\
\hline $\mathrm{C}_{2}$ & {$[0.5161 ; 0.4839]$} \\
\hline $\mathrm{C}_{3}$ & {$[0.3452 ; 0.3450 ; 0.3098]$} \\
\hline $\mathrm{C}_{4}$ & {$[0.4670 ; 0.5330]$} \\
\hline
\end{tabular}

\section{Result Analysis}

Enterprise Dimensions. In the internal system of enterprise, the completeness of the function settings and the degree of diversity of incentive measures are relatively more important. It shows that entrepreneurs pay more attention to the early stage of the work efficiency. In terms of Enterprise Maturity, internal collaboration and strategic planning are equally important. This shows that the strategic planning of entrepreneurial enterprises have a clear guiding role, and through the internal collaboration can make the strategy better implemented. In the aspect of enterprise staff quality, The proportion of experience members and Innovation ability are relatively more important. It suggests that the comprehensive quality of entrepreneurs is very important in the business start-up, and innovation will play a crucial role in the growth path of the enterprise. The level of employee turnover plays a decisive role in the stability of enterprises, and we can retain employees through good incentives.

Government Dimensions. Currently, the government of Wuhan has a lot of support policies for college students in terms of funds, including housing subsidies, exhibition subsidies, tax incentives, grants, etc. The scores of the measures are shown in Table 6.

As you can see money, tax incentives and other financial preferential policies have important influence on college students' entrepreneurial success, while the impact of policies such as advocacy and management services ranked the following.

Table 6 Each index score of the government dimensions

\begin{tabular}{|c|c|c|c|c|c|}
\hline $\begin{array}{c}\text { Government } \\
\text { measures }\end{array}$ & $\mathrm{C}_{5}$ & $\mathrm{C}_{6}$ & $\mathrm{C}_{7}$ & $\mathrm{C}_{8}$ & $\mathrm{C}_{9}$ \\
\hline Weight & 0.3415 & 0.1543 & 0.1042 & 0.3023 & 0.0977 \\
\hline
\end{tabular}

University Dimensions. College is the cradle of entrepreneurs in college. Therefore, in the analysis of the success factors of College students' entrepreneurship, universities play a pivotal role. The following results are obtained, as shown in table 7. 
Table 7 Each index score of the university dimensions

\begin{tabular}{|c|c|c|c|c|}
\hline $\begin{array}{c}\text { The entrepreneurial conditions } \\
\text { offered by the University }\end{array}$ & $\mathrm{C}_{10}$ & $\mathrm{C}_{11}$ & $\mathrm{C}_{12}$ & $\mathrm{C}_{13}$ \\
\hline Weight & 0.1762 & 0.4403 & 0.1503 & 0.2332 \\
\hline
\end{tabular}

The requirements of entrepreneurs on the comprehensive quality of entrepreneurs is relatively high. It often requires not only entrepreneurs have a profound theoretical accumulation, but also have a strong practical ability to operate. Therefore, the needs of college students for entrepreneurship education in Colleges and universities is relatively large. The accumulation of practical experience in school plays a vital role in the success of entrepreneurship in the future.

Based on the analysis of the above three dimensions. This study suggests that from within the enterprise point of view, the stability of College Students' entrepreneurial enterprises and the quality of their employees have a vital role in the long-term development of enterprises. And from the external factors, the support of the government's college students, especially the financial aid and preferential tax policies, plays a key role in the success of the enterprise. At the same time, the development of entrepreneurship education in Colleges is very necessary for college students in the initial stage of the role of boosting.

\section{Conclusion}

Through the above analysis, the following factors are proposed for the key factors influencing the success of college students' entrepreneurial enterprises.

Set up the College Students' Entrepreneurship Support Platform by Government. The government can refine measures to implement support policies in order to set up the college students' entrepreneurship support platform by government. At present, the state and local governments have introduced a number of preferential measures to support college students entrepreneurship and open a green channel for it[9]. The government should implement these measures through a variety of efficient and powerful channels, so that college students really feel the country for their business will give great support. Especially in terms of the financial support, The government can set up a special fund business, let students apply for approval, and compensate for the lack of small business loans to the lending rates, and give appropriate subsidies to provide strong financial backing for college students.

Constructing the System of Cultivating College Students' Entrepreneurial Ability. As the first line of College Students' ability training, universities should bear the responsibility to transfer knowledge, that is, through the industrialization of scientific and technological achievements and the realization of social services to the industry, to the community. At present, the cultivation of entrepreneurial ability in Wuhan universities is mainly focused on the theory of knowledge. In contrast, the ability of students to practice entrepreneurship is relatively lacking[10]. Therefore, colleges and universities can achieve the entrepreneurial spirit and entrepreneurial ability through the business plan competition, the construction of the entrepreneurial base, the business mentor system, entrepreneurial training and other practical training mode. Change the transfer learning into experiential learning, focus on entrepreneurship practice and effectively develop and utilize the whole social entrepreneurship resources and establish and improve the system of entrepreneurship education.

Make Full Use of Industry-university Interaction in the Promotion Role. Pay attention to the relationship between universities, enterprises and governments. The funding of the enterprise expands the academic research activities, at the same time, enterprises can profit from knowledge capitalization. University services to social and economic development, to solve many social problems, the government has benefited from it., while the University also received government policy and legal support. However, the current problem are: the weak corporate R \& D capabilities, "industry - college" seriously out of line; College teaching from the reality, the lack of communication between school and enterprise. University as a source of knowledge, when the 
production of knowledge is accumulated to the critical mass, it is possible to transform the spillover into productive forces and promote the development of enterprises and society. It can realize the capitalization of knowledge, and promote the development of economic.

Strengthen the Construction of Enterprise Internal Environment. Most studies show that the new enterprise, even a small retail business, all need experience in management, The reason why the majority of small businesses are stuck in small size is mismanagement. The enterprise must combine its own characteristics, adopt appropriate management measures, combined with the corresponding incentive mechanism and create a good corporate culture, improve employee loyalty to the enterprise, especially in the initial stage, low staff turnover rate for entrepreneurial students is very favorable and necessary; At the same time, optimize the allocation of resources, reduce the operating costs of enterprises and maximize the profits.

With the increasing employment pressure and the change of people's employment concept, College students self employment will become the another choice of more and more college students in the passive employment outside。And the success of entrepreneurial factors and college students to improve the success rate of entrepreneurial enterprises has become an urgent problem which need the joint efforts of all sectors of society.

\section{References}

[1] X. Yin and L. Zhang: Management \& Technology of SME, (2015) No.3, p. 115-116. (In Chinese)

[2] J. Wang: Research on the key factors of College Students' entrepreneurial success (Ph.D., East China University of Science and Technology, China 2013), p.9. (In Chinese)

[3] Dyer W G. Entrepreneurship Theory and Practice, Vol. 19 (1994) No.2, p.7-21.

[4] K.Q. Song: Entrepreneurial success (Economic Management Press, China 2002) (In Chinese)

[5] F.R. Xi: Heilongjiang Researches on Higher Education, Vol. 219 (2012) No.7, p.60-63. (In Chinese)

[6] C.H. Shen and L. Luo: Journal of Central South University (Social Sciences), Vol. 46 (2006) No.2, p. 231-235. (In Chinese)

[7] L. Tian and Y.P. Xu: Course Education Research, (2013) No.16, p.33-34. (In Chinese)

[8] C.J. Yang: Journal of Northeast Normal University (Philosophy and Social Sciences) Vol. 279 (2016) No.1, p.179-182. (In Chinese)

[9] X.M. Kong: China Metallurgical Education, Vol. 155 (2013) No.2, p.78-79+86. (In Chinese)

[10]X.Z. He: Research in Higher Education of Engineering, Vol. 159 (2016) No.4, p.90-94. (In Chinese) 